\title{
Firms' Patenting Activity and Performance: A Quantitative Analysis of Japanese Mobile Telecommunication Industry
}

\author{
Katsuhiro Suzuki \\ Global Information and Telecommunication Institute, \\ Faculty of Science and Engineering, Waseda University
}

\begin{abstract}
Mobile telecommunication industry has shown remarkable technological progress in these twenty years. Recently, cell phones in Japan are uniquely evolved to have high-tech functions such as one-seg television, high-speed internet connection and noncontact payment system. However, as described by a term "Galapagos syndrome", they are innovative but do not gain widespread use in the world.

In the present work, based on patent data, technological characteristics of R\&D activities in Japanese telecommunication carriers are investigated. Especially, the relationship between the $R \& D$ activities and subsequent firm's performances are analyzed. Similar to former studies concerning pharmaceutical and manufacturing industry, strong correlation between the number of patent applications and nets sales is found. It is also shown that regression model with shorter time-lag gives better description of the relationship between $R \& D$ inputs and outcome in this sector.

Furthermore, R\&D efficiency of each firm is investigated based on regression coefficients. It is found that $R \& D$ efficiencies of Japanese carries do not exceed that of Nokia, the leading company in world mobile telecommunication industry. The result implies that there exist room for improvement in $R \& D$ and market strategies for Japanese firms to expand their world market share.
\end{abstract}

\section{Introduction}

In 2008, total number of cellular subscribers in Japan reaches a hundred million, which corresponds to about eighty per cent of total population in Japan. In this highly saturated market, cellular carriers are playing a zero-sum game, scrambling to get customers away from competitors. Under such circumstances, keys to attract customers are the lowering of call rates, and innovative new functions based on cutting-edge technologies. In a thin chassis of a mobile phone with a thickness of about fifteen millimeters, outcomes from cutting-edge $R \& D$ activities such as ultra-small capacitors, organic EL panels and high-performance lithium ion batteries are installed.

In this paper, based on patent application data and registered patent data of each cellular carrier, we are to clarify the directions of R\&D and technological focuses in telecommunication industry in Japan. Based on panel analysis, we also investigate the relationship between the number of patent applications and performance indicators of firms such as the number of subscribers or net sales.

Mobile telecommunication is one of the most important industries where highly advanced technologies are required. The present analysis gives a basis for understanding technological and marketing strategies of main players in the industry.

\section{Research Background}

Patents are analyzed in a number of former studies since they are regarded as efficient basic data in studying firm's R\&D activities. For example, emergence and progress of new technologies can be analyzed quantitatively by using patent data [1]. New technology is assumed to be developed in the following way: (1) some basic and important inventions appear and a field of new technology emerges. (2) In order to develop and launch new products based on the technology, the number of patent applications increases to reach its peak. In this phase, both the important basic patents and peripheral patents appear. (3) After the launch of new products, the number of application begins to decrease. In [1], it is mentioned that emergence of basic patents may not have close relation to the peak of the patent applications, since it may depend on the development path of the specific technological field.

Patents are utilized not only for the study of technological development but also for the analysis of $R \& D$ of individual firms. The number of patent applications and that of registered patents are considered to be indicators to measure $\mathrm{R} \& \mathrm{D}$ activities. For example, Comanor and Scherer investigated the relationship between patents and sales of new products (measured for two years after its launch) in US pharmaceutical industry [2]. In this study, patent data of 57 firms in 1950's are utilized. 
They confirmed that there exist strong correlations between the patent applications and the sales with a time lag of 4 years. Recently, Ernst investigated 50 German machine tool manufacturers between 1984 and 1992 by panel analysis based on German domestic patent data and patents applied for European patent office [3]. Significant correlation between the patent applications and subsequent performances of firms is found with a time lag of 3 years. Like these works, there exist a lot of studies which support the existence of significant correlation between patenting activities and corporate performances ([4], [5], [6]). However, not all the preliminary studies support this kind of relationship. For example, Graham and Higgins analyzed 308 US pharmaceutical firms by using patents from 1985 to 2001 [7]. They concluded that there is no significant correlation between patents and sales of new products, though they followed same analytical method conducted by Comanor and Scherer. There may be some room for improvement in their analysis, for example, 16 years may be too long for correlation analysis. In fact, the data will contain the effects of economic fluctuations and that caused by the implementation of new pro-patent policy.

In the present study, we also use patent data to investigate R\&D activity, following former studies.

\section{Data}

XML patent data published monthly from Japan patent office are utilized in the present analysis. Since the performance of XML database is not so high for heavy-duty queries, we reconstruct faster Relational Database (RDB) by converting XML data to tables. As target firms, we adopt biggest three telecommunication carriers in Japan. We focus on the status and trend of R\&D activity of each carrier, and correlation between their performance and patenting activity. As an indicator for performance, the number of cell phone subscribers in Japan reported by Telecommunications Carriers Association (TAC) is used.

It is well known that telecom carriers in Japan have strong influence on manufactures of cell phones. They deeply involved in the development of new cell phones by manufactures from its early stage. Furthermore, it is not the manufactures but carriers who sell mobile phones to the subscribers. In Japan, there is no mean for subscribers to buy cell phones directly from the manufacturers. Therefore, it is important to grasp the R\&D activities of major carriers in understanding the technological trends in Japanese telecommunications industry.

By the way, in the past, there were more telecom carriers in Japan. In these twenty years, some firms are absorbed by others, or merged with each other to construct bigger carriers. By considering the historical paths of M\&A's, we relate all the patent applications (and registered patents) in the past to one of three major carriers. There are 127 applicant firms in our dataset. Among them, 27 firms are absorbed by NTT docomo, and therefore, patents applied by them are identified with those by NTT docomo in our analysis. Similarly, patents applied by other 41 firms are identified with au (KDDI), and 53 firms Softbank.

\section{Statistics on patenting activities}

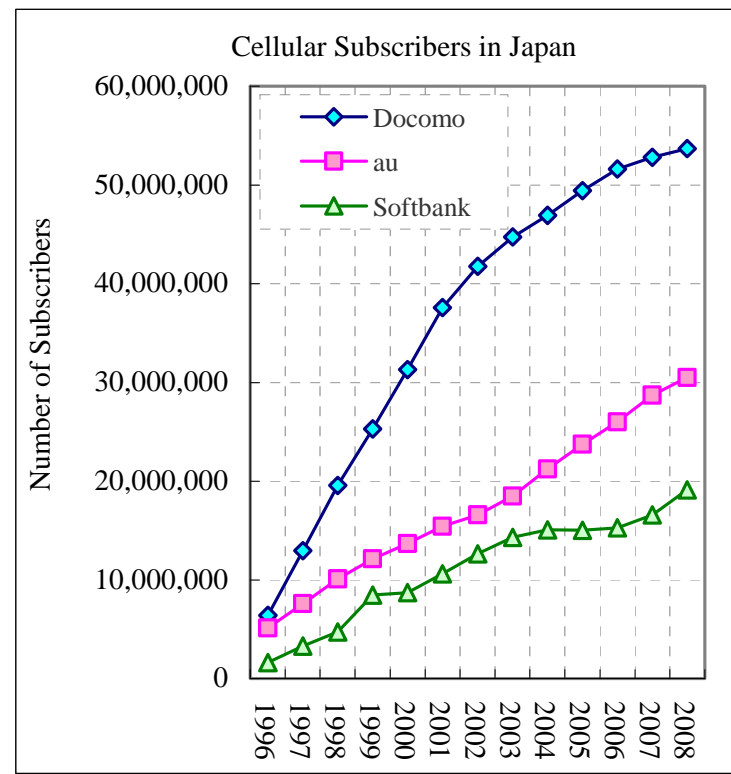

Figure 1. Number of cellular subscribers in Japan

In figure 1 , time series variations of cellular subscribers in Japan are shown. Recently, annual increase of subscribers is about 5 million, and total subscribers of these three carriers exceed a hundred million in 2008. Among these carriers, NTT Docomo is dominant which own more than 50\% share of total subscribers. Since NTT was once a governmental organization with high credibility, NTT Docomo's dominance is not surprising.

Concerning the growth rate of these three carriers, each of the three is different from the other two. From 1996 to 2002, Docomo shows remarkable growth rate, however, from 2003 to 2006, the growing rate of au exceeds that of Docomo. And recently, from 2007, Softbank shows top rate of growth among three.

As for the number of patent applications and registration ratio, they are shown in figure 2 and figure 3 , respectively. In these graphs, years on the abscissa are determined by the application date of each patent. Concerning the patent applications, Docomo has been a dominant player since 1998, occupying about 68 percent of the total applications by these three carriers. This share is rather high 
compared to the fact that Docomo have 52 percent share of total cell subscribers in 2008.

In Japan, applicant of a patent can request for the examination of the patent within three years after its application. In figure 3, the ratio by the number of registered patents to patent applications is plotted from 1990 to 2007. From 1990 to 1993, au shows high registration ratio higher than $80 \%$. It must be taken into the account simultaneously that the numbers of patent applications by au are not so high in this period. From 1994, the ratio of au began to decrease. It has been staying below $60 \%$ for subsequent 12 years, though the number of patent application was monotonically increasing.

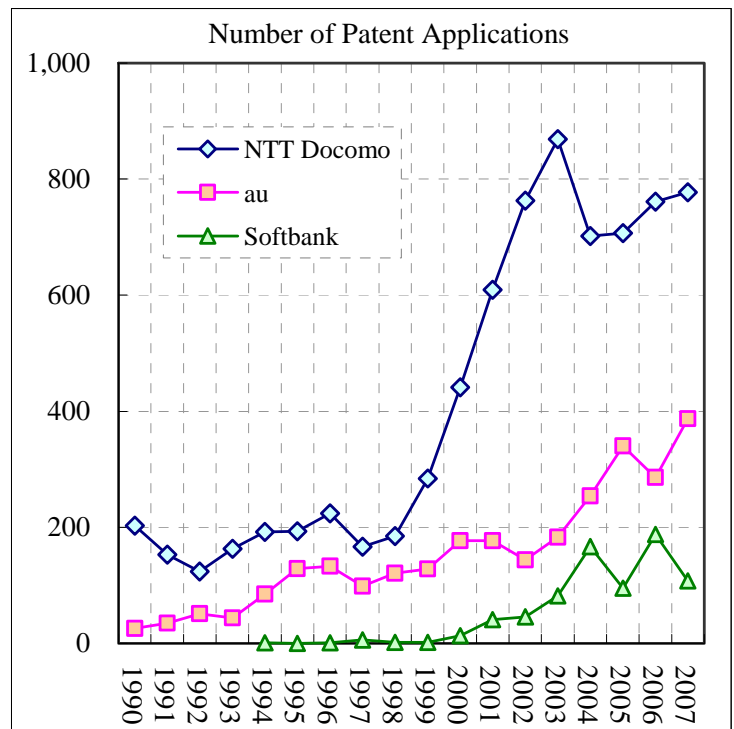

Figure 2. Patent applications from major cellular carriers in Japan

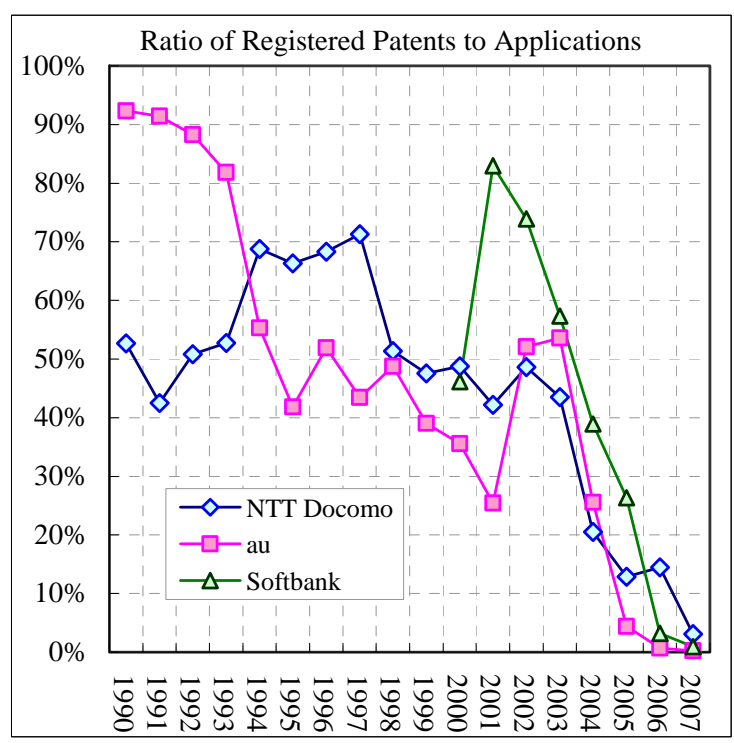

Figure 3. Ratio of number of registered patents to applications
In contrast, the ratio of Docomo exceeded 70\% from 1994 to 1997, which suggests internal consistency between R\&D activities and IP strategy. However, after 1998, the ratio of Docomo decreased to stay below 55\%, as it was before 1993 .

Patent applications by Softbank, the latest entrant to the telecom market, have been increasing since 2001. Though the number of applications is less than those of two other carriers, Softbank's R\&D is considered to be active enough since more than a hundred patents have been applied for each year. During the period 2001-2005, it is worth mentioning that Softbank's ratio of issued patents to applications is highest among three carriers. It is plausible that active and consistent R\&D was conducted in Softbank, in order to overcome disadvantages as a latest entrant. As described below, strong correlation between the number of applications and subscribers is found in this dataset. It is worth paying attention to the patenting activities of Softbank in the near future to predict its growth.

\section{Technological characteristics}

In this section, we briefly summarize the distribution of technological elements involved in the patent applications by major carriers in Japan. In Table 1, top eight IPC codes (subclass level) are shown according to their appearance frequencies. These subclasses are considered to represent $R \& D$ activities in Japanese telecommunication industry since they occupy more than eighty percent of total IPC codes in this dataset.

IPC code which appears most frequently is "H04Q" (SELECTING OF SWITCHES, RELAYS, SELECTORS, WIRELESS NETWORKS), having a $17 \%$ share of total codes. In the second place and third one, "H04L" (TRANSMISSION OF DIGITAL INFORMATION) has a 16.5\% share, and "G06F" (ELECTRIC DIGITAL DATA PROCESSING) 14\%, respectively.

The distribution of IPC codes in applications from Docomo is similar to the statistics described above, since it dominates the patent applications in this industry. Concerning au and Softbank, different IPC codes take higher places. As for au, it is worth mentioning that "H04N" (PICTORIAL COMMUNICATION, e.g. TELEVISION) takes second place, with a $13 \%$ share. Other IPC subclasses which have large shares are "H04L" and "H04B" related to transmission technology. Since Docomo and au are two of the oldest telecom carriers in Japan, these subclasses appear commonly in their applications. Concerning Softbank, distribution of IPC codes is quite different from those of top two carriers. In fact, "H04M" (TELEPHONIC COMMUNICATION: 27\%) takes the first place, and "G06F" (ELECTRIC DIGITAL DATA PROCESSING: 27\%) the second. These two IPC 
subclasses occupy more than $50 \%$ of the patent applications from Softbank, while IPC codes with regard to transmission technology have only a $12 \%$ share. As a latest entrant, Softbank seems to be engaged in $R \& D$ concerning data processing or applications rather than elementary telecommunication technology. Focused R\&D strategy of Softbank may serve as a useful reference for other carriers and cell phone manufacturers in Japan, in order to develop their shares in the global market.

\section{Correlations between the number of patent applications and that of subscribers}

In the following, we investigate the relationship between R\&D activities and firms’ performances. In the former studies, as an indicator of firm's performance, sales of new products or market value per share are utilized.

Table 1. IPC subclasses frequently appear in the dataset

\begin{tabular}{|c|c|c|c|c|c|c|c|c|c|c|c|c|c|}
\hline \multicolumn{5}{|c|}{ Patent Applications: 1990-2007 } & \multicolumn{3}{|c|}{ NTT Docomo } & \multicolumn{3}{|c|}{ au (KDDI) } & \multicolumn{3}{|c|}{ Softbank } \\
\hline $\begin{array}{c}\text { IPC } \\
\text { (Subclass) }\end{array}$ & Description & $\begin{array}{l}\text { \# of Patent } \\
\text { Applications }\end{array}$ & $\begin{array}{l}\text { \# of } \\
\text { Registe } \\
\text { red } \\
\text { Patents }\end{array}$ & Ratio & $\begin{array}{l}\text { \# of Patent } \\
\text { Applications }\end{array}$ & $\begin{array}{l}\text { \# of } \\
\text { Registe } \\
\text { red } \\
\text { Patents }\end{array}$ & Ratio & $\begin{array}{l}\text { \# of Patent } \\
\text { Applications }\end{array}$ & $\begin{array}{l}\text { \# of } \\
\text { Registe } \\
\text { red } \\
\text { Patents }\end{array}$ & Ratio & $\begin{array}{c}\text { \# of Patent } \\
\text { Applications }\end{array}$ & $\begin{array}{l}\text { \# of } \\
\text { Registe } \\
\text { red } \\
\text { Patents }\end{array}$ & Ratio \\
\hline $1 \mathrm{H} 04 \mathrm{Q}$ & $\begin{array}{l}\text { SEECTING } \\
\text { (switches, relays, } \\
\text { selectors, wireless } \\
\text { com. netw orks ) }\end{array}$ & $1,877(17 \%)$ & 848 & $45 \%$ & $1,610(21 \%)$ & 755 & $47 \%$ & $159(6 \%)$ & 50 & $31 \%$ & $108(14 \%)$ & 37 & $34 \%$ \\
\hline 2 HO4L & $\begin{array}{l}\text { TRANSMSSION } \\
\text { OF DIGTAL } \\
\text { INFORMATION, } \\
\text { e.g. TELEGRAPHIC } \\
\text { COMMUNICATION }\end{array}$ & $1,832(17 \%)$ & 703 & $38 \%$ & 1,130 (15\%) & 489 & $43 \%$ & $642(23 \%)$ & 166 & $26 \%$ & $60 \quad(8 \%)$ & 34 & $57 \%$ \\
\hline 3 G06F & $\begin{array}{l}\text { 日ECTRIC } \\
\text { DIGTAL DATA } \\
\text { PROCESSING }\end{array}$ & 1,613 (15\%) & 223 & $14 \%$ & 1,069 (14\%) & 144 & $13 \%$ & $342(12 \%)$ & 44 & $13 \%$ & $202(27 \%)$ & 29 & $14 \%$ \\
\hline 4 H04B & $\begin{array}{l}\text { TRANSMSSION } \\
\text { (transmission } \\
\text { systems for } \\
\text { measured values, } \\
\text { control or similar } \\
\text { signals, digital } \\
\text { information, etc.) }\end{array}$ & $1,456(13 \%)$ & 573 & $39 \%$ & $1,070(14 \%)$ & 432 & $40 \%$ & $356(13 \%)$ & 114 & $32 \%$ & $30 \quad(4 \%)$ & 12 & $40 \%$ \\
\hline $5 \mathrm{HO4M}$ & $\begin{array}{l}\text { TEPHONIC } \\
\text { COMMUNCATION }\end{array}$ & $987(9 \%)$ & 334 & $34 \%$ & $613(8 \%)$ & 208 & $34 \%$ & $168(6 \%)$ & 48 & $29 \%$ & $206(27 \%)$ & 66 & $32 \%$ \\
\hline $6 \mathrm{HO4N}$ & $\begin{array}{l}\text { PICTORIAL } \\
\text { COMMINICATION, } \\
\text { e.g. TELEVISION }\end{array}$ & $620(6 \%)$ & 229 & $37 \%$ & $232(3 \%)$ & 53 & $23 \%$ & $3 \varpi 3(13 \%)$ & 151 & $42 \%$ & $25 \quad(3 \%)$ & 11 & $44 \%$ \\
\hline $7 \mathrm{HO4J}$ & $\begin{array}{l}\text { MULTIPLEX } \\
\text { COMMUNCATION }\end{array}$ & $397 \quad(4 \%)$ & 151 & $38 \%$ & $283(4 \%)$ & 104 & $37 \%$ & $110(4 \%)$ & 38 & $35 \%$ & $4 \quad(1 \%)$ & 0 & $0 \%$ \\
\hline 8 H01Q & $\begin{array}{l}\text { AERIALS } \\
\text { (microw ave radiators } \\
\text { for near-field } \\
\text { therapeutic treatment, } \\
\text { wav eguides, } \\
\text { radiators or aerials for } \\
\text { microw ave heating) }\end{array}$ & $336(3 \%)$ & 161 & $48 \%$ & $297(4 \%)$ & 133 & $45 \%$ & $34(1 \%)$ & 20 & $59 \%$ & $5 \quad(1 \%)$ & 1 & $20 \%$ \\
\hline & Subtotal & $9,118(82 \%)$ & 3,222 & $35 \%$ & $6,304(84 \%)$ & 2,318 & $37 \%$ & $2,174 \quad(78 \%)$ & 631 & $29 \%$ & $640(85 \%)$ & 190 & $30 \%$ \\
\hline & Total & $11,068(100 \%)$ & 3,723 & $35 \%$ & $7,517(100 \%)$ & 2,673 & $36 \%$ & $2,799(100 \%)$ & 823 & $29 \%$ & 752 (100\%) & 227 & $30 \%$ \\
\hline
\end{tabular}


However, the mobile telecom industry has been developed very rapidly in these ten years. Especially, in Japan, it seems that the market has entered next maturity phase. In this section, at first, we utilize the number of subscribers as an indicator to investigate the firm's performance, since it is considered to be less affected by the change of market phase than sales amount.

In Figure 4, scatter plot of number of patent applications versus that of subscribers is shown. Strong correlation can be confirmed by the regression line which corresponds to a simple pooling model without time lag. As described, in former studies, significant correlations between patent applications and corporate performances are observed in several industries. Cellular communication industry is considered to be similar to the pharmaceutical industry in the sense that the outcome of $R \& D$ will directly contribute to the differentiation of the final products by implementing new functions or new services. It is also considered that such a strong correlation may be a characteristic property of rapidly developing market which is based on high-technologies.

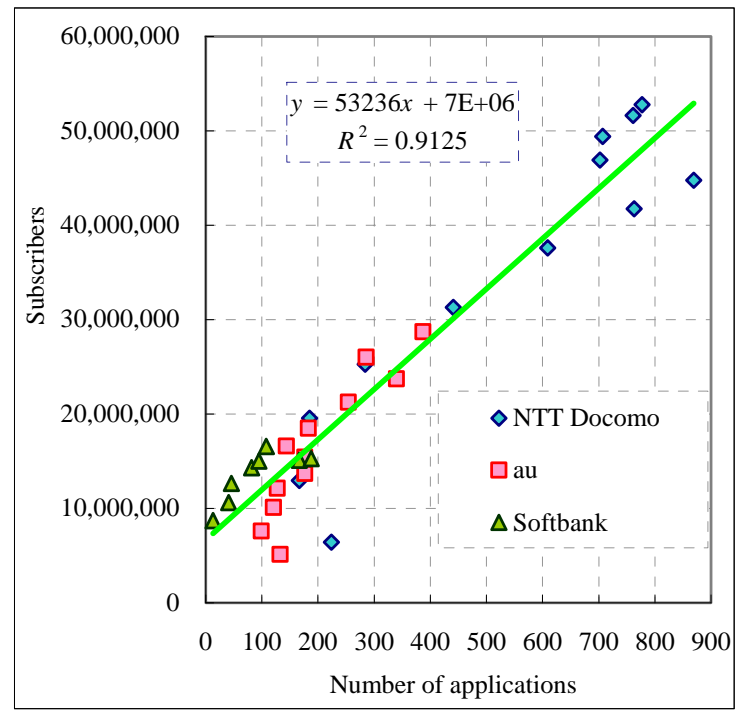

Figure 4. Scatter plot of number of patent applications versus that of subscribers without time lag

In former studies, time-lagged variables are introduced to describe the relationship between R\&D inputs and outcomes. In Table 2, results of regression analyses for the time lags from 0 year to 3 years are shown. For each time lag, determination coefficient is high enough and P-values show that all models are acceptable at $0.1 \%$ confidence level. However, as the time lag increases, both the value of determination coefficient and p-value decrease. Therefore, it is found that for cellular industry, pooling models with shorter time lag gives better description.
Table 2. Effect of time lag on regression (dependent variable: number of subscribers)

\begin{tabular}{lrrrr}
\hline $\begin{array}{c}\text { Time-lag } \\
(\mathrm{Yr})\end{array}$ & $\mathbf{0}$ & $\mathbf{1}$ & $\mathbf{2}$ & $\mathbf{3}$ \\
\hline R2 & 0.96 & 0.95 & 0.93 & 0.90 \\
R2 Adj. & 0.91 & 0.91 & 0.87 & 0.81 \\
p-value & $2.03 \mathrm{E}-17$ & $1.59 \mathrm{E}-15$ & $2.79 \mathrm{E}-12$ & $5.32 \mathrm{E}-09$ \\
\hline Intercept & $6,663,880$ & $9,021,677$ & $11,560,129$ & $14,048,254$ \\
p-value & $3.95 \mathrm{E}-06$ & $7.44 \mathrm{E}-08$ & $5.54 \mathrm{E}-08$ & $3.73 \mathrm{E}-07$ \\
\hline Coefficient & 53,236 & 53,125 & 52,496 & 51,677 \\
p-value & $2.03 \mathrm{E}-17$ & $1.59 \mathrm{E}-15$ & $2.79 \mathrm{E}-12$ & $5.32 \mathrm{E}-09$ \\
\hline
\end{tabular}

In [2], one way fixed effect model extended with time lagged variables is introduced as follows:

$$
S_{i, t}=c_{i}+\sum_{k} b_{k} P_{i, t-k}+\varepsilon_{i, t}
$$

where $i$ denotes firms, $t$ year, and $k$ time lag in years, respectively. $S_{i, t}$ is the dependent variable (such as net sales or the number of subscribers) of the firm $i$ in the year $t$, while $P_{i, t-k}$ the number of patents of the firm $i$ in the year $t-k \cdot \varepsilon_{i, t}$ is an error term, and $c_{i}$ denotes the intercept which represents the fixed effect of the firm $i$. In [2], as a result of the analysis by introducing $k$ 's from 0 to 3 years, time lag effect in German machine tool manufacturing industry is estimated to be about 2 or 3 years.

If one is trying to apply this model for other dataset, in order to obtain a stable estimation of coefficients, independent variables must not be highly correlated each other. However, in our dataset, it is found that patent applications with different time lags are highly correlated each other. Therefore, in the following, we utilize the usual model without time lag, i.e., $k=0$.

In usual panel analysis, three models, i.e., pooling model, fixed-effect model and random-effect model are considered. In order to select most suitable model, statistical hypothesis test is applied for each pair of models, by adopting simpler model as a null hypothesis. We utilized the software "eviews" for the test of each pair of models. For the present dataset, it is found that the random effect model is identical with the pooling model, since error term concerning cross sectional effect disappears. Therefore, pooling model and fixed effect model are compared.

In Table 3, result of F test is shown. Estimated Pvalue $(42 \%)$ is quite large, thus, corresponding null hypothesis cannot be rejected. In this dataset, it is found that the pooling model is sufficient enough to describe the relationship between the number of patent applications and that of subscribers. 
Table 3. F test for pooling model and fixed effect model

\begin{tabular}{llll}
\hline & Statistic & d.f. & p-value \\
\hline Cross-section F & 0.899642 & $(2,32)$ & 0.4168
\end{tabular}

\section{Correlation between the number of patent applications and sales}

Next, the correlation between the number of patent applications and net sales is investigated. In order to investigate both marketing strategy and pricing one of each firm, net sales is considered to be more suitable variable than the number of subscribers. In Figure 5, scatter plot of the number of patent applications versus net sales without a time-lag is shown. In contrast to Figure 4, the growth of dependent variable is suppressed in the $\mathrm{x}$-range higher than 700. As a result of market maturation, the decline in the unit price of mobile telecommunication is considered to suppress the growth of net sales. Therefore, the determination coefficient of Figure 5 is smaller than that in Figure 4 , however, the value of which is still high enough to imply strong correlation.

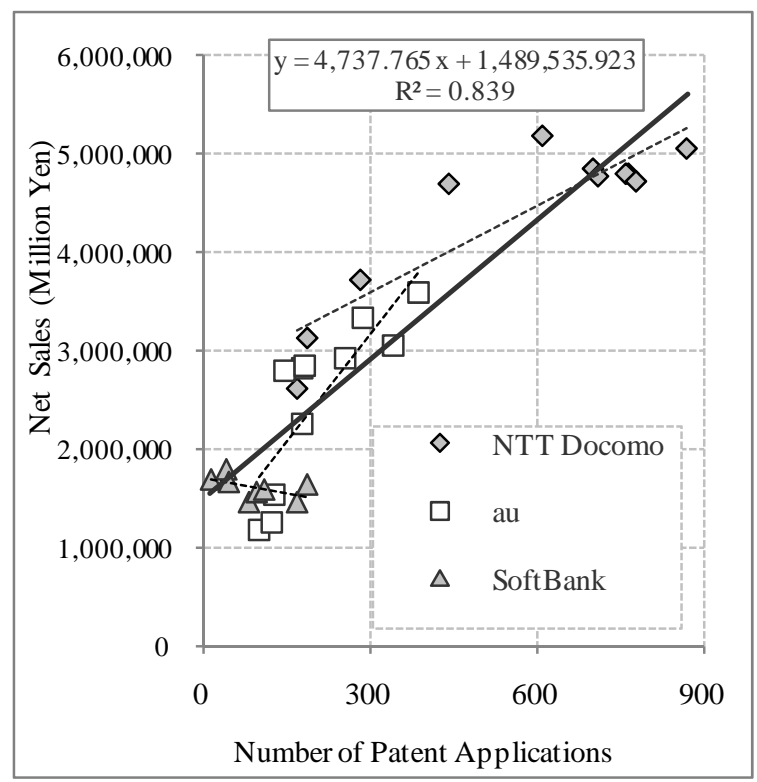

Figure 5. Scatter plot of patent applications versus subscribers without a time lag

In Table 4, effects of time-lags for independent variable are described. For any time-lag, corresponding regression is significant at $0.05 \%$ confidence level. Similar to Table 2, adjusted $R^{2}$ decreases as the time-lag increases, however, in this case, sharper decline is observed. In fact, for a timelag of three years, adjusted $R^{2}$ for net sales is only 0.53 , which is about $65 \%$ of corresponding value in the case of subscribers. Therefore, similar to the result described in former section, for the pooling model concerning net sales, it is found that shorter time-lag gives better model.

It is worth mentioning that the present dataset concerning net sales is different from the one concerning subscribers because each firm shows different behavior. In Figure 5, the regression model concerning pooling data is drawn as a bold solid line, while dotted lines represent the models based on data of each single firm. It is obvious that the slopes of the dotted lines are quite different. For example, as for Softbank, the regression line has a negative slope.

Table 4. Effect of time lag on regression (dependent variable: net sales)

\begin{tabular}{lrrrr}
\hline $\begin{array}{c}\text { Time-lag } \\
\text { (Yr) }\end{array}$ & $\mathbf{0}$ & $\mathbf{1}$ & $\mathbf{2}$ & $\mathbf{3}$ \\
\hline R2 & 0.91 & 0.86 & 0.79 & 0.73 \\
R2 Adj. & 0.83 & 0.73 & 0.62 & 0.53 \\
p-value & $5.41 \mathrm{E}-12$ & $4.29 \mathrm{E}-10$ & $4.47 \mathrm{E}-07$ & $2.59 \mathrm{E}-05$ \\
\hline Intercept & $1,487,074$ & $1,668,539$ & $1,932,117$ & $2,191,549$ \\
p-value & $1.78 \mathrm{E}-09$ & $1.45 \mathrm{E}-09$ & $1.35 \mathrm{E}-08$ & $3.86 \mathrm{E}-08$ \\
\hline Coefficient & 4,742 & 4,742 & 4,192 & 3,922 \\
p-value & $5.41 \mathrm{E}-12$ & $5.41 \mathrm{E}-12$ & $5.41 \mathrm{E}-12$ & $5.41 \mathrm{E}-12$ \\
\hline
\end{tabular}

In order to describe the differences of firms, one way models introduced in the previous section are not considered to be adequate. In fact, in both "one way fixed effect model" and "one way random effect model”, individual characters of firms are only reflected on intercepts, keeping the slope constant. Instead, more flexible models are considered to be suitable. In order to represent the differences in both the intercepts and slopes, we adopt SUR model without time-lag as follows [10]:

$$
\begin{aligned}
& \text { Sales }=\left\{C(1)+\text { Dum }_{a u} C(2)+\text { Dum }_{S B} C(3)\right\} \\
& +\left\{C(4)+\text { Dum }_{a u} C(5)+\text { Dum }_{S B} C(6)\right\} \times \text { Patent }+\varepsilon,
\end{aligned}
$$

where $D_{u m}$ and $D_{\text {um }}$ are dummy variables for au and Softbank, respectively. The coefficients and intercepts in this model can be estimated by using EGLS method. As a result, adjusted $R^{2}$ is found to be very high (0.953), which implies this model can describe the relationship between patent applications and sales very well. Estimated coefficients are displayed in table 5.

Table 5. Estimated coefficients (SUR model)

\begin{tabular}{lrrrl}
\hline & Coeff. & Std. Error & t-Statistic & Prob. \\
\hline C(1) & 2872741 & 273989.9 & 10.48484 & 0.0000 \\
C(2) & -1917206 & 382361 & -5.014124 & 0.0000 \\
C(3) & -1130478 & 277941.5 & -4.067324 & 0.0005 \\
C(4) & 2663.714 & 440.4482 & 6.047735 & 0.0000 \\
C(5) & 4778.042 & 1399.179 & 3.41489 & 0.0024 \\
C(6) & -4059.42 & 673.4365 & -6.027918 & 0.0000 \\
\hline
\end{tabular}


In order to confirm the validity of SUR model, we compared it with other models (pooling model, one way fixed effect model) by using Walt test. For both cases, null hypotheses are rejected at one per cent confidence level, thus, SUR model is supported (Table 6 (a) , 6(b)).

Table 6 (a). Result of Walt test to compare one way fixed effect model with SUR model

\begin{tabular}{lccr}
\hline & Value & D. F. & Probability \\
\hline F-statistic & 31.73174 & $(2,23)$ & 0.0000 \\
Chi-square & 63.46347 & 2 & 0.0000 \\
\hline
\end{tabular}

Table 6 (b). Result of Walt test to compare pooling model with SUR model

\begin{tabular}{lccc}
\hline & Value & D. F. & Probability \\
\hline F-statistic & 7.415064 & $(4,23)$ & 0.0005 \\
Chi-square & 29.66026 & 4 & 0.0000 \\
\hline
\end{tabular}

Regression coefficient and intercept of each firm are shown in Table 7. Among these, the former is considered to be important since it describes the growth amount of net sales per a patent application. Both the effects of R\&D and that of sales strategy are considered to be reflected to them. The regression coefficients are quite different among these three firms: for example, the coefficient of au is three times larger than that of NTT Docomo. Furthermore, as mentioned previously, Softbank has a negative slope.

Table 7. Estimated coefficients (JP Carriers)

\begin{tabular}{lrr}
\hline & Coefficient & Intercept \\
\hline NTT Docomo & 2,664 & $2,872,741$ \\
Au & 7,442 & 955,535 \\
Softbank & $-1,396$ & $1,742,263$ \\
\hline
\end{tabular}

This coefficient can be considered to be a kind of measure to quantify how directly closed innovation in each firm is connected to sales. In other words, differences in strategies concerning the procurement of key technologies can be measured by this coefficient. For example, for firms which develop original products or services, a larger coefficient is considered to be more favorable.

\section{Comparison with Nokia}

Lastly, in this section, we analyze Nokia, one of the world leading telecommunication companies, in order to make comparison with Japanese firms. Since Nokia is not a carrier, we focus on the relationship between patent applications and sales.

\subsection{Data}

It is well known that Nokia is a multinational company which dominates world cell phone market (except Japan) [11]. In order to investigate $R \& D$ activity of a global company based on patents, it is ideal to acquire all data of patent applications in all countries. However, as for a company which makes profits from almost all the major markets in the world (in a balanced manner), it is plausible that almost all its patent applications are filled under Patent Cooperation Treaty (PCT). In fact, PCT applications are quite useful to avoid complicated operations concerning IP strategy for global companies. In analyzing Nokia, we utilize the number of PCT applications as an indicator to measure its R\&D activities.

Similar to Japanese carriers, the correlation between the number of applications and net sales is very high. In Table 8, the effect of time-lag on determination coefficient of simple regression model is shown: similar to Table 4 , adjusted $R^{2}$ decreases as the time-lag increases. Therefore, in this case, regression without time-lag is, once again, found to be a best model.

Table 8. Effect of time lag on regression (Nokia: PCT applications vs net sales)

\begin{tabular}{lllll}
\hline $\begin{array}{c}\text { Time-lag } \\
\text { (Yr) }\end{array}$ & $\mathbf{0}$ & $\mathbf{1}$ & $\mathbf{2}$ & $\mathbf{3}$ \\
\hline R2 & 0.95 & 0.89 & 0.84 & 0.62 \\
R2 Adj. & 0.90 & 0.79 & 0.71 & 0.39 \\
p-value & $1.01 \mathrm{E}-05$ & $6.05 \mathrm{E}-04$ & $4.24 \mathrm{E}-03$ & $9.98 \mathrm{E}-02$ \\
\hline Intercept & $-1,923,043$ & $-1,343,116$ & $-326,558$ & $1,304,638$ \\
p-value & $2.09 \mathrm{E}-02$ & $2.36 \mathrm{E}-01$ & $7.93 \mathrm{E}-01$ & $5.05 \mathrm{E}-01$ \\
\hline Coefficient & 7,475 & 7,559 & 6,864 & 5,272 \\
p-value & $1.01 \mathrm{E}-05$ & $6.05 \mathrm{E}-04$ & $4.24 \mathrm{E}-03$ & $9.98 \mathrm{E}-02$ \\
\hline
\end{tabular}

\subsection{Comparison of firm's $R \& D$ efficiency}

Estimated regression coefficient and intercept of Nokia are displayed in Table 9.

Table 9. Estimated coefficients (Nokia)

\begin{tabular}{ccc}
\hline & Coefficient & Intercept \\
\hline Nokia & 7,475 & $-1,923,042$ \\
\hline
\end{tabular}

As expected, regression coefficient of Nokia is high enough. In fact, it is slightly higher than that of au in Table 7, which implies that R\&D activities in Nokia are reflected efficiently to the growth of its sales. One of the supposable reasons for high R\&D efficiency in Nokia and au is that they might separate in-house development and outsourcing effectively. For example, it is well known that au acquires its 
core telecommunication technology from Qualcomm. Therefore, it is plausible that R\&D efforts in au are mainly devoted to services and functions in higher technological layers. As a result of such strategic technological management, high R\&D efficiency is considered to be attained.

As for NTT Docomo, though its R\&D efficiency is lower than that of Nokia and au, there exists positive high correlation between patent applications and sales. Docomo, an oldest carrier in Japan, has strong R\&D ability to launch original high-tech services, such as "i-mode". It is conceivable that the essence of its strategy is to make the most of its dominant share in the market by developing its original telecommunication platform and high-tech services. If a firm only pursues R\&D efficiency, inhouse development of ALL technologies is not indispensable. However, as a leader of Japanese telecommunication industry, Docomo has been developing useful services and functionality in-house without outsourcing, in order to differentiate them from competitors, enhancing royalty of customers. Strategy like this is considered to be quite effective for a firm in a dominant position of a market, and at least in Japan, it has been successful.

In contrast to three firms described above, Softbank is quite unique since its R\&D efficiency is found to be negative. The result implies that the R\&D efforts in the firm contribute to the decline in sales. However, it is considered to be a temporary phenomenon as a result of a strategy implemented by a latest-comer to the market. In fact, Softbank, entered into the market in 2006, has been putting stress on increasing market share without thought of profit. It is conceivable that the strategy will be changed if a certain amount of share is obtained in the near future.

\section{Summary and future work}

In the present analysis, based on patent data, technological property of Japanese cellular industry is investigated. It is found that, recently, Softbank, the latest entrant to the market, is conducting quite active R\&D after 2003. Furthermore, distribution of technological elements in Softbank's patent applications is different from those of NTT Docomo and au. The strategy of Softbank may give some hints for Japanese telecom carriers and cell phone manufacturers to develop more shares in the international market.

Concerning the relationship between R\&D inputs and corporate performance, as a result of panel data analysis, strong correlation between the number of patent applications and that of subscribers is found. In this industry, simple pooling model without a time lag is selected to be a best-fitting model. As for the relationship between patent applications and net sales, though the determination coefficient of pooling model is high enough (0.83), we adopt SUR model in order to describe the differences among firms in detail. Similar to the pooled analysis with timelagged variables based on the number of subscribers, SUR model without time-lag is found to be best. In addition, Nokia, the world leading company in mobile telecommunication industry, is analyzed based on PCT applications and net sales. Also in this case, simple regression without time-lag is found to be the best-fitting model.

The lack of time-lag in several models is considered to be a unique character of this industry. In fact, in the former studies concerning pharmaceutical industry and machine tool industry, time-lag of 2 to 4 years are reported. Relatively speaking, mobile telecommunication industry is considered to be similar to pharmaceutical industry in the sense outcomes of R\&D activities are rather directly related to the differentiation of final products. However, a mobile phone can be regarded as a kind of computer implemented with a small CPU, and therefore, similar to computer industry, technological progress in mobile telecommunication industry is very rapid. Lack of time-lag in several statistical models in the present study is considered to be consistent with the technological background of this industry.

In the present work, R\&D efficiency of each firm is also investigated based on correlation coefficient. It is found that R\&D efficiency of Nokia and au is high, which implies that the R\&D efforts in both firms are effectively reflected to their sales performances. As for NTT Docomo, the efficiency is lower than those of Nokia and au, however, it is positive. It is conceivable that Docomo, the leader of Japanese telecommunication industry, implements strategies to enhance their dominant market share by developing original technologies and platforms without outsourcing. In contrast, R\&D efficiency of Softbank is found to be negative, since they put stress on increasing market share without thought of profit.

If a Japanese firm intends to expand market share in the world telecommunication market, the value of R\&D efficiency of Nokia is considered to be a good numerical target; in order to win in highly competitive market, excellent business turnover must be achieved while devoting sufficient and necessary efforts in cutting-edge $\mathrm{R} \& \mathrm{D}$.

In the near future, we are going to investigate the world cellular industry in detail by adding more external data, by expanding the analysis in the present work.

\section{References}

[1] Basberg, B. L., "Patents and the measurement of technological change: A survey of the literature”, Research Policy, Vol. 16, 1987, pp.131-141. 
[2] Comanor, W. S. and Sherer, F. M., "Patent Statistics as a Measure of Technical Change", Journal of Political Economy, Vol. 77, 1969, pp. 392-398.

[3] Erntst, H., "Patent applications and subsequent changes of performance: evidence from time-series crosssection analyses on the firm level”, Research Policy 30, 2001, pp. 143-157.

[4] Scherer, F. M., "Corporate inventive output, profits and growth", The Journal of Political Economy , Vol. 73, 1965, pp. 290-297.

[5] Austin, D. H., “An event-study approach to measuring innovative output: the case of biotechnology", American Economic Review, Vol. 83, 1993, pp. 253-258.

[6] Austin, D. H., “The power of patents”, Resources, Vol. 119, 1995, pp. 2-5.

[7] Graham, S. J. and Higgins, M. J., "Comanor and Scherer Revisited: Do Patents Proxy for New Product Introductions?”, SSRN digital archive, 2007, 1024572.

[8] Kodama, F., "Emerging Patterns of Innovation", Harvard Business School Press, 1995.

[9] Verspagen, B., "Measuring Intersectoral Technology Spillovers: Estimates from the European and US Patent Office Databases", Economic Systems Research 49, 1996, pp. 47-65.

[10] Zellner, A., "An Efficient Method of Estimating Seemingly Unrelated Regressions and Tests for Aggregation Bias”, Journal of the American Statistical Association Vol. 57, No. 298, 1962, pp. 348-368.

[11] Steinback, D., "Winning across the global markets How Nokia creates strategic advantage in a fast-changing world”, Jossey-Bass, 2010. 